\title{
PARÂMETROS PRODUTIVOS DO FEIJÃO VERMELHO EM FUNÇÃO DO TAMANHO DE SEMENTES
}

\author{
Robson Pelissari Drun ${ }^{1}$, Sibila Grigolo ${ }^{2}$, Ana Carolina da Costa Lara Fioreze ${ }^{1}$, Samuel Luiz Fioreze ${ }^{1}$ \\ Universidade Federal de Santa Catarina-UFSC, Curitibanos, SC. Universidade do Estado de Santa Catarina - UDESC, \\ Centro de Ciências Agroveterinárias - CAV, Lages, SC. E-mail: robsondrun20@gmail.com
}

\section{RESUMO}

O tamanho do grão é uma característica de interesse para seleção precoce na cultura do feijoeiro comum. O presente trabalho teve por objetivo avaliar a influência do tamanho da semente sobre os componentes da produção e parâmetros morfológicos das sementes de feijão. $\mathrm{O}$ experimento foi conduzido em cultivo protegido no período entre setembro e dezembro de 2015. As sementes de feijão foram selecionadas e classificadas em quatro classes de tamanho com base na largura e comprimento, dentro de uma população de feijão vermelho (Dark Red Kidney), pertencente ao grupo gênico Andino, com ampla variabilidade para tamanho de grão. As plantas foram cultivadas em vasos de polietileno, com volume de $11 \mathrm{dm}^{3}$, utilizandose delineamento experimental de blocos casualizados com quatro tratamentos e cinco repetições. Foram avaliados o número de dias para emergência de $50 \%$ das plântulas e para emergência no número máximo de plantas em cada parcela. Ao final do ciclo da cultura foram determinados os componentes da produção e a produção de grãos por planta, além das dimensões das sementes. 0 tamanho das sementes se manteve após um ciclo de cultivo, sem que houvesse diferenças na produção total de grãos. A seleção com base no tamanho de sementes apresenta potencial para ser utilizada em feijão comum pertencente ao grupo gênico Andino.

Palavras - chave: melhoramento; Phaseolus vulgaris; produtividade.

\section{YIELD TRAITS OF RED BEAN AS AFFECTED BY SEED SIZE}

\begin{abstract}
Seed size can be an interesting trait to early selection on common bean crop. This work aimed to study the influence of the seed size on the yield components and morphologic parameters of common bean seeds. The experiment was carried out in green house conditions, during September and December 2015. Seeds were selected and classified in four size classes according to width and length, within a local population of red bean (Dark Red Kidney), belonging to the Andean group of dispersion and showing high variability for seed size. Plants were cultivated on $11 \mathrm{dm}^{3}$ polyethylene pots, in experimental design of randomized complete blocks with five replications. Were evaluated the duration of the period to get $50 \%$ and the maximum plant emergence in each plot. At the end of plant cycle, were determined the yield and yield components, as well as seed dimensions. Seed size was maintained after one crop cycle, without affects grain yield. Selection based on the seed size shows potential to be used in Andean group of common bean.
\end{abstract} Keywords: crop breeding; Phaseolus vulgaris; yield.

\section{INTRODUÇÃO}

A produtividade de grãos da cultura do feijão comum (Phaseolus vulgaris L.) é altamente correlacionada com os seus componentes da produção, como o número de vagens por planta, número de grãos por planta e massa média de grãos (COSTA; ZIMMERMANN, 1988; RAMOS JÚNIOR et al., 2005). Dependendo das condições, alguns componentes da produção podem aumentar e outros diminuir, promovendo a manutenção da estabilidade produtiva (CASQUERO et al., 2006). Variações no tamanho de sementes podem ocorrer em função do ambiente de cultivo, associadas à competição entre drenos (GREVEN et al., 1997; EGLI; BRUENING, 2001) ou como efeito de variações genéticas, entre ou dentro de genótipos (KOINANGE et al., 1996). 
Embora alguns trabalhos apontem para uma relação negativa entre o tamanho das sementes e a produtividade do feijoeiro (WHITE; GONZÁLEZ, 1990; SEXTON et al., 1997), é bastante frequente a observação de que o uso de sementes grandes promove maior velocidade de estabelecimento e crescimento inicial de plantas de feijão (PERIN et al., 2002; CANGUSSÚ et al., 2013; AMBIKA et al., 2014; SEIF et al., 2016) em condições de campo, e principalmente em condições de estresse (GHOLAMI et al., 2009).

Além de sua relação com a produtividade da cultura, o tamanho da semente tem efeito direto no processo de semeadura, sendo que 0 uso de sementes menores pode resultar em redução de custos de semeadura. Outra implicação em relação ao tamanho da semente se refere ao mecanismo dosador (PORTELLA, 2001), visto que sementes com tamanhos e formas mais homogêneas possivelmente irão facilitar o manuseio pelos mecanismos dosadores das semeadouras.

O feijoeiro comum foi domesticado de forma independente em dois centros primários, na América Central e México e no sul dos Andes, além de um centro secundário, ao norte dos Andes (GEPTS; DEBOUCK, 1991). A domesticação nos dois centros primários levou à formação de dois conjuntos gênicos principais, um Mesoamericano e um Andino, entre os quais existe uma série de diferenças morfológicas, fisiológicas e genéticas (GEPTS; DEBOUCK, 1991; $\mathrm{SINGH}, 1991$ ). Entre as diferenças morfológicas pode-se citar o tamanho das sementes, que é maior em genótipos do grupo Andino (BORÉM, 2005).

$\mathrm{Na}$ grande maioria dos estados brasileiros, existe uma preferência de cultivo entre os feijões com sementes pequenas, como o feijão carioca, que é aceito em quase todo o Brasil e o preto, sendo consumido em toda a região sul e parte da região sudeste. Feijões que apresentam grãos grandes, contudo, ainda são pouco aceitos e os programas de melhoramento genético atuam de maneira bem inicial nesses genótipos. $\mathrm{O}$ tamanho da semente em feijão tem herança com efeito materno, sendo importante considerar qual o genitor será o parental feminino em cruzamentos (MESQUITA, 1989).

Genótipos com menor grau de melhoramento genético, ou que apresentam ainda locos gênicos em heterozigose, podem apresentar variabilidade genética para parâmetros morfológicos de sementes, como tamanho e peso. Desta forma, apesar de o maior tamanho de sementes ser característico de materiais genéticos do Grupo Andino, alguns genótipos podem apresentar variabilidade para esta característica, a qual pode ser explorada em programas de melhoramento. Considerando que parâmetros morfológicos de sementes podem potencialmente ser características herdáveis, tais parâmetros poderiam ser utilizados para se realizar a seleção dentro destes materiais. Neste sentido, o presente trabalho teve por objetivo estudar a influência do tamanho da semente sobre os componentes da produção e parâmetros morfológicos de sementes de feijão.

\section{MATERIAL E MÉTODOS}

$O$ experimento foi conduzido em cultivo protegido na área da estação experimental do Centro de Ciências Rurais da Universidade Federal de Santa Catarina, localizado no município de Curitibanos (SC). A área experimental está localizada nas coordenadas geográficas $27^{\circ} 17^{\prime} 12.2^{\prime \prime} \mathrm{S}, 50^{\circ} 31^{\prime} 96.6^{\prime \prime} \mathrm{O}$ e a uma altitude média de $1010 \mathrm{~m}$. Segundo a classificação de Köppen, Curitibanos está em uma região de clima tipo $\mathrm{Cfb}$ - clima temperado, com verão ameno (CLIMATE-DATA, 2017).

$O$ delineamento experimental utilizado foi $o$ de blocos casualizados com quatro tratamentos e cinco repetições. As sementes foram classificadas em quatro classes de tamanho, com base na largura e espessura, mensuradas com o uso do paquímetro digital e determinadas pelos seguintes intervalos: 1) Largura de 6,03 a 7,56 $\mathrm{mm}$ e comprimento de 10,59 a $13,02 \mathrm{~mm}$; 2) Largura de 6,62 a $8,92 \mathrm{~mm}$ e comprimento de 12,98 a $16,76 \mathrm{~mm}$; 3) Largura de 7,82 a $9,30 \mathrm{~mm}$ e comprimento de 15,54 a $17,48 \mathrm{~mm}$ e 4) Largura de 8,31 a $9,81 \mathrm{~mm}$ e comprimento de 16,42 a $19,14 \mathrm{~mm}$. O material utilizado no estudo foi obtido através de seleção para tamanho de semente em uma população local de plantas do feijão vermelho (Dark Red Kidney), pertencente ao grupo gênico Andino, com ampla variabilidade para tamanho de grão. A seleção das sementes foi realizada em laboratório, após a colheita de uma área cultivada em condições de campo durante a safra 2014/15 em sistema de semeadura direta, seguindo-se as recomendações técnicas para o cultivo do feijoeiro no estado.

A implantação do experimento foi realizada em 25 de setembro de 2015 em vasos de polietileno com volume de $11 \mathrm{dm}^{3}$, 
preenchidos com um cambissolo háplico de textura argilosa, com $524 \mathrm{~g} \mathrm{~kg}^{-1}$ de argila, $7,2 \mathrm{~g} \mathrm{~kg}^{-}$ ${ }^{1}$ de areia e $404 \mathrm{~g} \mathrm{~kg}^{-1}$ de silte (EMBRAPA, 2006). Antes de ser acondicionado nos vasos, o solo foi peneirado, corrigido e adubado. Foram utilizados, $1,51 \mathrm{~g} \mathrm{dm}^{-3}$ de calcário, $0,13 \mathrm{~g} \mathrm{dm}^{-3}$ de cloreto de potássio $\left(60 \%\right.$ de $\left.\mathrm{K}_{2} \mathrm{O}\right)$ e $1,82 \mathrm{~g} \mathrm{dm}^{-3}$ de superfosfato triplo. Foram semeadas quatro sementes por vaso, mantendo-se duas plantas uniformes após desbaste realizado no estádio V1. Antes da semeadura, as sementes foram tratadas com produto comercial à base de fipronil, piraclostrobina e metil tiofanato (Standak Top ${ }^{\circ}$ ). Aos 7, 21 e 35 dias após a emergência das plantas, foram realizadas adubações nitrogenadas de cobertura, na dose de $25 \mathrm{mg} \mathrm{dm}^{-}$ ${ }^{3}$ de $\mathrm{N}$, utilizando como fonte a Uréia ( $45 \%$ de N) diluída em água.

Após a implantação do experimento, determinou-se 0 número de dias para emergência de $50 \%$ das plântulas e para emergência no número máximo de plantas em cada parcela. As plantas foram conduzidas de acordo com as recomendações técnicas para o cultivo do feijoeiro até o final do ciclo, que ocorreu aos 90 dias após a emergência. Após a colheita, determinou-se o número de vagens chochas, número de vagens viáveis (contendo sementes), número total de vagens e número de grãos por planta. A massa de grãos por planta e a massa de cem grãos foram corrigidas para $13 \%$ de umidade após secagem em estufa de circulação forçada de ar. Com o auxílio de um paquímetro digital, determinou-se o comprimento e a largura das sementes em cada uma das plantas, a partir dos quais foram determinadas as dimensões médias das sementes e a variância dentro de cada amostra.

Os dados foram submetidos à análise de variância pelo teste $\mathrm{F}(p \leq 0,05)$. Para a comparação das médias foi aplicado o teste de Tukey $(p \leq 0,05)$. Foram também obtidos os coeficientes de correlação de Pearson entre os componentes produtivos das plantas.

\section{RESULTADOS E DISCUSSÃO}

O tamanho das sementes não afetou o período para emergência de $50 \%$ das plantas da parcela, tampouco o período para a obtenção da emergência máxima de plantas (Tabela 1). Entre os parâmetros produtivos, houve efeito das classes de semente sobre o número de vagens chochas, número de grãos por planta e massa de cem grãos, sendo que a massa de grãos por planta não foi afetada. Para os parâmetros associados às dimensões das sementes colhidas, houve efeito significativo para o comprimento e largura médios e máximos, enquanto os demais parâmetros não foram afetados.

Tabela 1. Quadrados médios da análise de variância para dias para emergência de emergência de plântulas, parâmetros produtivos e dimensões de sementes de feijão vermelho (Dark Red Kidney) de uma variedade local. Curitibanos (SC), 2015.

\begin{tabular}{cccccccccc}
\hline $\mathrm{FV}^{1}$ & $\mathrm{GL}^{2}$ & DPE1 & DPE2 & NVCH & NVV & NVT & NGP & MGP & MCG \\
\hline Classe & 3 & $0,13^{\text {ns }}$ & $1,93^{\text {ns }}$ & $12,98^{*}$ & $2,98^{\text {ns }}$ & $6,48^{\text {ns }}$ & $412,36^{*}$ & $13,53^{\text {ns }}$ & $379,05^{* *}$ \\
Bloco & 4 & 0,58 & 1,31 & 1,83 & 2,27 & 3,28 & 46,82 & 4,93 & 90,79 \\
Erro & 12 & 0,18 & 2,26 & 3,53 & 2,37 & 4,03 & 85,16 & 7,42 & 30,21 \\
\hline CV (\%) & & 6,54 & 22,64 & 37,03 & 18 & 14,74 & 29,39 & 19,7 & 11,35 \\
\hline FV & GL & COMED & COVAR & COMAX & COMIN $^{\text {COMED }}$ & LAVAR $^{\text {LAMAX }}$ & LAMAX $^{\text {LAMIN }}$ \\
\hline Classe & 3 & $11,16^{* *}$ & $4,01^{\text {ns }}$ & $14,21^{* *}$ & $12,04^{\text {ns }}$ & $1,58^{* *}$ & $1,36^{\text {ns }}$ & $4,75^{* *}$ & $1,67^{\text {ns }}$ \\
Bloco & 4 & 2,16 & 6,67 & 1,92 & 6,42 & 0,39 & 1,06 & 1,45 & 1,54 \\
Erro & 12 & 0,86 & 18,83 & 1,07 & 5,53 & 0,22 & 1,67 & 0,45 & 1,82 \\
\hline CV (\%) & & 5,82 & 80,44 & 5,67 & 24,14 & 5,4 & 69,14 & 6,57 & 26,20 \\
\hline
\end{tabular}

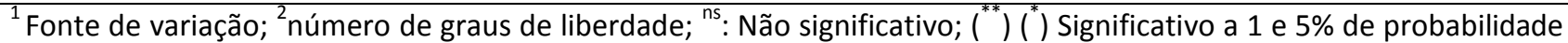
pelo teste $\mathrm{F}$, respectivamente; DPE1: dias para a emergência de $50 \%$ das plantas; DPE2: dias para a emergência máxima de plantas; NVCH: número de vagens chochas; NVV: número de vagens viáveis, NTV número total de vagens; NGP: número de grãos por planta; MGP: massa de grãos por planta; MCG: massa de cem grãos; COMED: comprimento médio de grãos; COVAR: variância amostral para comprimento de grãos; COMAX: comprimento máximo de grãos; COMIN: comprimento mínimo de grãos; LAMED: largura média de grãos; LAVAR: variância amostral para largura de grãos; LAMAX: largura máxima de grãos; LAMIN: largura mínima de grãos. 
Em várias culturas, o tamanho das sementes é considerado um dos fatores que determina a duração do período entre semeadura e emergência de plântulas, em função da quantidade de reservas energéticas acumuladas (LIMA, 1997; CARVALHO; NAKAGAWA, 2000; PÁDUA et al., 2010). Em condições de campo, observa-se que plantas oriundas de sementes grandes apresentam maior vigor, crescimento e produção de grãos (AMBIKA et al., 2014). Cangussú et al. (2013) estudando a cultivar de feijão 'Manteigão Vermelho', pertencente ao grupo andino, observaram que sementes com maior tamanho apresentam maior qualidade fisiológica e acúmulo inicial de matéria seca.
Apesar de ser frequentemente observado na literatura, no presente trabalho, o tamanho das sementes não afetou 0 tempo para emergência das plantas (Tabela 2). Este comportamento pode estar associado à ausência de condições desfavoráveis para a germinação e emergência, por se tratar de um experimento em cultivo protegido. $O$ efeito do tamanho de sementes sobre a velocidade de emergência e vigor inicial de plantas é, mais comumente, observado em condições limitantes, seja em função de restrições hídricas ou excessos térmicos. Gholami et al. (2009) observaram que sementes grandes apresentaram maior germinação e vigor de plântulas quando submetidas à estresse por seca ou salinidade.

Tabela 2. Dias para emergência de emergência de plântulas e parâmetros produtivos plantas de feijão vermelho (Dark Red Kidney) de uma variedade local, em função da classe de tamanho de semente. Curitibanos (SC), 2015.

\begin{tabular}{ccccccccc}
\hline Classe & DPE1 & DPE2 & NVCH & NVV & NVT & NGP & MGP & MCG \\
\hline 1 & 6,2 & 6,8 & $3,6 \mathrm{~b}$ & 9,0 & 12,6 & $42,3 \mathrm{a}$ & 15,3 & $36,8 \mathrm{c}$ \\
2 & 6,4 & 5,8 & $3,9 \mathrm{~b}$ & 8,8 & 12,7 & $33,4 \mathrm{ab}$ & 14,4 & $48,4 \mathrm{~b}$ \\
3 & 6,6 & 7,0 & $5,8 \mathrm{ab}$ & 9,0 & 14,8 & $29,5 \mathrm{bc}$ & 14,2 & $52,3 \mathrm{ab}$ \\
4 & 6,4 & 7,2 & $7,0 \mathrm{a}$ & 7,4 & 14,4 & $20,4 \mathrm{c}$ & 11,5 & $56,6 \mathrm{a}$ \\
\hline
\end{tabular}

${ }^{1}$ Dimensões das sementes: 1) Largura de 6,03 a 7,56 mm e comprimento de 10,59 a 13,02 mm; 2) Largura de 6,62 a $8,92 \mathrm{~mm}$ e comprimento de 12,98 a $16,76 \mathrm{~mm}$; 3) Largura de 7,82 a 9,30 mm e comprimento de 15,54 a $17,48 \mathrm{~mm}$ e 4) Largura de 8,31 a 9,81 mm e comprimento de 16,42 a 19,14 mm. DPE1: dias para a emergência de 50\% das plantas; DPE2: dias para a emergência máxima de plantas; NVCH: número de vagens chochas; NVV: número de vagens viáveis, NTV número total de vagens; NGP: número de grãos por planta; MGP: massa de grãos por planta; MCG: massa de cem grãos. Médias seguidas por letras diferentes, na coluna diferem significativamente pelo teste de Tukey a $5 \%$ de probabilidade.

O número de vagens chochas foi maior em plantas oriundas da classe 4 de tamanho de sementes (Tabela 2). Os menores valores foram observados para as classes 1 e 2 , sendo que a classe 3 apresentou valores intermediários. Apesar das alterações observadas para esta característica, o número total de vagens e o número de vagens viáveis não foram afetados pelo tamanho das sementes. Assim, pode-se considerar que sementes maiores geram plantas com maior potencial de emissão de vagens, contudo, algum fator regulatório deve limitar a quantidade de vagens viáveis.

O tamanho de sementes apresentou correlação positiva com o número total de vagens, contudo a correlação foi negativa com o número de vagens viáveis (Tabela 3 ), indicando que o aumento na quantidade de vagens pode provocar uma maior competição entre drenos, que resulta na diminuição no tamanho das sementes. O número de vagens chochas apresentou correlação negativa com o número de grãos por planta, porém a correlação foi positiva quanto à massa de cem grãos e ao comprimento médio de grãos, evidenciando que apesar de plantas oriundas de sementes maiores produzirem uma maior massa de cem grãos e maior comprimento, o número de vagens chochas também será maior e consequentemente haverá um menor número de grãos por planta. 
Tabela 3. Coeficientes de correlação de Person (r), entre as variáveis analisadas nas quatro classes de tamanho de semente do feijão vermelho (Dark Red Kidney) de uma variedade local.

\begin{tabular}{|c|c|c|c|c|c|c|c|}
\hline & NVV & NVT & NGP & MGP & MCG & COMED & LAMED \\
\hline $\mathrm{NVCH}$ & $-0,42$ & $0,72^{* *}$ & $-0,70^{* *}$ & $-0,47^{*}$ & $0,57^{* *}$ & $0,62^{* *}$ & 0,40 \\
\hline NVV & & 0,31 & $0,70^{* *}$ & $0,76^{* *}$ & $-0,38$ & $-0,38$ & $-0,15$ \\
\hline NVT & & & $-0,20$ & 0,08 & 0,31 & 0,36 & 0,30 \\
\hline NGP & & & & $0,81^{* *}$ & $-0,78^{* *}$ & $-0,82^{* *}$ & $-0,64^{* *}$ \\
\hline MGP & & & & & $-0,34$ & $-0,41$ & $-0,21$ \\
\hline MCG & & & & & & $0,98^{* *}$ & $0,89^{* *}$ \\
\hline COMED & & & & & & & $0,91^{* *}$ \\
\hline
\end{tabular}

$\left(^{* *}\right)($ () Significativo a 1 e $5 \%$ de probabilidade pelo teste $t$, respectivamente; $\mathrm{NVCH}$ : número de vagens chochas; NVV: número de vagens viáveis; NVT: número de vagens total; NGP: número de grãos por planta; MGP: massa de grãos por planta; MCG: massa de cem grãos; COMED: comprimento médio de grãos; e LAMED: largura média de grãos.

O número de grãos foi superior em plantas oriundas das menores sementes (classe 1), sendo os menores valores observados em plantas originadas da classe quatro (Tabela 2). Plantas oriundas das classes dois e três apresentaram valores intermediários. Apesar da diferença significativa para o número de grãos, a massa de grãos por planta não foi afetada pelas classes de sementes estudas. Este comportamento é um reflexo do maior peso médio de grãos encontrado em plantas oriundas de sementes grandes (classe quatro), decrescendo em função do tamanho da semente.

Houve efeito das classes de semente para a massa de cem grãos, com maiores valores encontrados em plantas oriundas da classe quatro e menor massa encontrada em plantas da classe um (Tabela 2). As classes dois e três apresentaram valores intermediários. Com isso, fica evidente a existência de um efeito compensatório com relação negativa entre número de grãos por planta e a massa de cem grãos, que pode ser observado através da análise de correlação (Tabela 3).

Perin et al. (2002) estudando três cultivares de feijão de centros de domesticação distintos observaram que sementes grandes proporcionaram plantas com maior altura, maior índice de área foliar, e maior acúmulo de biomassa de raiz e de parte aérea, contudo, os componentes da produção e a produção de grãos não foram afetados. Seif et al. (2016) observaram maior crescimento, acúmulo de matéria seca e nutrientes em plantas de feijão oriundas de sementes grandes, que resultaram em maior número e produção de grãos em condições de campo, os quais apresentaram maior tamanho e teor de proteínas. Lima et al. (2005) estudaram o crescimento e os parâmetros produtivos de cultivares de feijoeiro pertencentes aos grupos andino e mesoamericano e observaram que plantas oriundas de sementes maiores apresentam maior crescimento, acúmulo de matéria seca inicial e massa de cem grãos, enquanto plantas oriundas de sementes pequenas apresentam maior taxa de crescimento relativo e assimilação de carbono. Os autores observaram que plantas oriundas de sementes pequenas apresentam mecanismos compensatórios responsáveis pela manutenção da produtividade de grãos, quando comparadas com plantas oriundas de sementes grandes.

As dimensões das sementes (comprimento e largura) foram maiores nas classes 3 e 4 (Tabela 4). Além dos valores médios, o comprimento e a largura máxima de sementes também foram superiores em plantas oriundas de sementes maiores, enquanto os valores mínimos para estas características não foram afetados. A correlação positiva significativa entre as dimensões da semente e o peso de cem grãos é apresentada na Tabela 3. A correlação entre comprimento e peso de sementes foi de 0,98, enquanto para a correlação entre largura e massa de sementes o valor de correlação foi de 0,89 , indicando que o fator comprimento médio de grãos apresenta maior influência sobre o peso de sementes. Resultados semelhantes foram encontrados por Ribeiro et al. (2000) avaliando as relações entre as dimensões e peso de cem sementes de feijão entre os grupos preto, carioca e colorido. 
Tabela 4. Dimensões das sementes de feijão vermelho (Dark Red Kidney) de uma variedade local em função da classe de tamanho de semente. Curitibanos (SC), 2015.

\begin{tabular}{ccccccccc}
\hline Classe & COMED & COVAR & COMAX & COMIN & LAMED & LAVAR & LAMAX & LAMIN \\
\hline 1 & $13,9 \mathrm{c}$ & 4,14 & $15,9 \mathrm{~b}$ & 7,4 & 7,84 & $7,8 \mathrm{~b}$ & $9,1 \mathrm{~b}$ & 4,3 \\
2 & $15,9 \mathrm{~b}$ & 5,37 & $18,0 \mathrm{a}$ & 10,3 & 8,62 & $8,6 \mathrm{a}$ & $9,9 \mathrm{~b}$ & 5,4 \\
3 & $16,7 \mathrm{ab}$ & 5,96 & $19,3 \mathrm{a}$ & 10,5 & 9,10 & $9,1 \mathrm{a}$ & $11,5 \mathrm{a}$ & 5,2 \\
4 & $17,4 \mathrm{a}$ & 6,11 & $19,7 \mathrm{a}$ & 10,7 & 8,96 & $9,0 \mathrm{a}$ & $10,3 \mathrm{ab}$ & 5,6 \\
\hline
\end{tabular}

${ }^{1}$ Dimensões das sementes: 1) Largura de 6,03 a 7,56 mm e comprimento de 10,59 a 13,02 mm; 2) Largura de 6,62 a $8,92 \mathrm{~mm}$ e comprimento de 12,98 a $16,76 \mathrm{~mm}$; 3) Largura de 7,82 a 9,30 mm e comprimento de 15,54 a $17,48 \mathrm{~mm}$ e 4) Largura de 8,31 a $9,81 \mathrm{~mm}$ e comprimento de 16,42 a 19,14 $\mathrm{mm}$. Médias seguidas por diferentes letras na coluna diferem significativamente pelo teste de Tukey a $5 \%$ de probabilidade; COMED: comprimento médio de grãos; COVAR: variância amostral para comprimento de grãos; COMAX: comprimento máximo de grãos; COMIN: comprimento mínimo de grãos; LAMED: largura média de grãos; LAVAR: variância amostral para largura de grãos; LAMAX: largura máxima de grãos; LAMIN: largura mínima de grãos.

Os resultados obtidos no presente estudo indicam a possibilidade de realizar a seleção com base no tamanho de sementes de feijão, visto que a característica parece se manter de um ciclo para outro no cultivo deste material. Desta forma, uma seleção precoce com base no tamanho de sementes pode resultar em economia de tempo no processo de melhoramento, visto que algumas características como vigor e rápido crescimento inicial estão associadas ao maior tamanho de grãos, como descrito anteriormente. A seleção precoce para tamanho de grão foi eficiente para o aumento desse caráter em população de feijão caupi (CRUZIO, 2014). Contudo, ainda são necessários estudos para identificar a relação entre 0 tamanho de sementes e o rendimento a campo em materiais genéticos pertencentes ao grupo Andino, visto que para materiais do grupo Mesoamericano maiores rendimentos parecem estar associados a materiais com sementes pequenas (DALLA CORTE et al., 2010).

\section{CONCLUSÕES}

- Plantas de feijão vermelho oriundas de sementes grandes mantém 0 tamanho de sementes após um ciclo de cultivo, apresentando correlação negativa com o número de sementes por planta;

- A característica de tamanho de sementes apresenta potencial para seleção precoce em plantas de feijão vermelho.

\section{REFERÊNCIAS}

AMBIKA, S.; MANONMANI, V.; SOMASUNDARAM, $G$. Review ond effect of seed size on seedling vigour and seed yield. Research Journal of Seed
Science, v. 7, p. 31-38, 2014. https://doi.org/10.3923/riss.2014.31.38

BORÉM, A. Melhoramento de espécies cultivadas. Viçosa: UFV, 2005. 969 p.

CANGUSSÚ, L.V.S.; DAVID, A.M.S.S.; AMARO, H.T.R.; ASSIS M.O. Efeito do tamanho de sementes no desempenho fisiológico de feijoeiro. Pesquisa Agropecuária Gaúcha, v. 19, p. 71-79, 2013.

CARVALHO, N.M.; NAKAGAWA, J. Sementes: ciência, tecnologia e produção. Jaboticabal: FUNEP, 4ed. 588p. 2000.

CASQUERO, P.A.; LEMA, M., SANTALLA, M.; DE RON, A.M. Performance of common bean (Phaseolus vulgaris L.) landraces from Spain in the Atlantic and Mediterranean environments. Genetic Resources and Crop Evolution, v.53, p. 1021-1032, 2006. https://doi.org/10.1007/s10722-004-7794-1

CLIMATE-DATA. Dados climáticos para cidades mundiais. Disponível em: <http://pt.climatedata.org/>. Acesso em: 10 jun. 2017.

COSTA, J. C. G.; ZIMMERMANN, M. J. O. Melhoramento genético. In: ZIMMERMANN, M. J. O.; ROCHA, M.; YAMADA, T. (Eds.). A cultura do feijoeiro: fatores que afetam a produtividade. Piracicaba: Potafós, 1988. p. 229-245.

CRUZIO, A. S. Eficiência da seleção precoce para tamanho de grão e seu efeito em outros caracteres de feijão-caupi. 2014. 79 p. 
Dissertação (Mestrado) - Universidade Federal de Lavras, 2014.

DALLA CORTE, A.; MODA-CIRINO, V; ARIAS, C.A.A.; TOLEDO, J.F.F.; DESTRO, D. Genetic analysis of seed morphological traits and its correlations with grain yield in common bean. Brazilian Archives of Biology and Technology, v. 53, p.27-34, 2000.

https://doi.org/10.1590/S1516$\underline{89132010000100004}$

EGLI, D.B.; BRUENING, W.P. Source-sink relationships, seed sucrose levels and seed growth rates in soybean. Annals of Botany, v.88, p.235-242, 2001. https://doi.org/10.1006/anbo.2001.1449

EMBRAPA. Centro Nacional de Pesquisa de Solos. Sistema brasileiro de classificação de solos. 2. ed. Rio de Janeiro: EMBRAPA, 2006. 306 p.

EMBRAPA. BRS Embaixador, cultivar de feijão comum com tipo de grão para exportação. Goiás: EMBRAPA, 2007.

GEPTS, P.; DEBOUCK, D. Origin, domestication, and evolution of the common bean (Phaseolus vulgaris L.). In: SCHOONHOVEN, A.; VOYSEST, O. (Eds.). Common beans: research for crop improvement. Cali: CIAT, 1991. p.7-53.

GHOLAMI, A.; SHARAFI, S.;SHARAFI, A.; GHASEMI, $S$. Germination of different seed size of pinto bean cultivars as affected by salinity and drought stress. Journal of Food, Agriculture \& Environment, v. 7, p. 555-558, 2009.

GREVEN, M.M.; MCKENZIE, B.A.; HILL, G.D. The influence of stress on yield, abortion and seed size of French dwarf beans (Phaseolus vulgaris L.). Proceedings in Agronomy Society of New Zealand, v.27, p.101-108, 1997.

KOINANGE, E.M.K.; SINGH, S.P.; GEPTS, P. genetic control of the domestication syndrome in common bean. Crop science, v.36, p.1037-1045, 1996.

https://doi.org/10.2135/cropsci1996.0011183X0 $\underline{03600040037 x}$

LIMA, R.M. Efeito do tamanho das sementes sobre alguns atributos fisiológicos e agronômicos. Brasília: ABRASEM, 1997. 168 p.
LIMA, E.R.; SANTIAGO, A.S.; ARAÚJO, A.P.TEIXEIRA, M.G. Effects of the seed size of sown seed on growth and yield of common bean cultivars of different seed sizes. Brazilian journal of Plant Physiology, v.17, p.273-281, 2005. https://doi.org/10.1590/S167704202005000300001

MESQUITA, I.A. Efeito materno na determinação do tamanho da semente do feijoeiro (Phaseolus vulgaris L.). 1989, 70 f. Dissertação (Mestrado) Universidade Federal de Lavras, Lavras-MG, 1989.

PADUA, G.P.; ZITO, R.K.; ARANTES, N.E.; FRANÇA NETO, J. B. Influência do tamanho da semente na qualidade fisiológica e na produtividade da cultura da soja. Revista Brasileira de Sementes, v. 32, p.9-12, 2010. https://doi.org/10.1590/S0101$\underline{31222010000300001}$

PERIN, A.; ARAÚJO, A.P.; TEIXEIRA, M.G. Efeito do tamanho da semente na acumulação de biomassa e nutrientes e na produtividade do feijoeiro. Pesquisa Agropecuária Brasileira, v. 37, p. 1711-1718, 2002.

https://doi.org/10.1590/S0100$\underline{204 \times 2002001200006}$

PORTELLA, A.P. Semeadoras para plantio direto. Viçosa: Aprenda Fácil, 230 p. 2001.

RAMOS JUNIOR, E.U.; LEMOS, L.B.; SILVA, T.R.B. Componentes da produção, produtividade de grãos e características tecnológicas de cultivares de feijão. Bragantia, v.64, p.75-82, 2005. https://doi.org/10.1590/S0006$\underline{87052005000100008}$

RIBEIRO, N.D.; MELLO, R.M.; STORCK, L. Variabilidade e interrelações das características morfológicas das sementes de grupos comerciais de feijão. Revista Brasileira de Agrociência, v.6, p.213-217, 2000.

SEIF, Y.I.A.; EL-MINIAWY, S. E.M.; EL-AZM, N.A.I.A.; HEGAZI, A.Z. Response of snap bean growth and seed yield to seed size, plant density and foliar application with algae extract. Annals of Agricultural Science, v.61, p.187-199, 2016. https://doi.org/10.1016/i.aoas.2016.09.001

SEXTON, P.J.; PETERSON, C.M.; BOOTE, K.J.; WHITE, J.W. Early-season growth in relation to 
region of domestication, seed size, and leaf traits in common bean. Field Crops Research, v. 52, p. 69-78, $1997 . \quad$ https://doi.org/10.1016/S03784290(96)03452-1

SINGH, S.P.; GEPTS, P.; DEBOUCK, D.G. Races of common bean (Phaseolus vulgaris, Fabaceae). Economic Botany, v.45, p. 379-396, 1992. https://doi.org/10.1007/BF02887079

WHITE, J.W.; GONZÁLEZ, A. Characterization of the negative association between seed yield and seed size among genotypes of common bean. Field Crops Research, v. 23, p. 159-175, 1990. https://doi.org/10.1016/0378-4290(90)90052-D

Recebido para publicação em 04/07/2017

Revisado em 03/01/2018

Aceito em 24/01/2018 